\title{
CORRECTION
}

View Article Online

View Journal I View Issue

W) Check for updates

Cite this: RSC Adv., 2020, 10, 42339

\section{Correction: A 3-D NanoMagnetoElectrokinetic model for ultra-high precision assembly of ferromagnetic NWs using magnetic-field assisted dielectrophoresis}

\author{
Sachin K. Singh, ${ }^{a}$ Md Mahadi Rajib, ${ }^{\mathrm{b}}$ Justine L. Drobitch, ${ }^{\mathrm{C}}$ Jayasimha Atulasimha, ${ }^{\mathrm{b}}$ \\ Supriyo Bandyopadhyay ${ }^{\complement}$ and Arunkumar Subramanian*a \\ Correction for 'A 3-D NanoMagnetoElectrokinetic model for ultra-high precision assembly of \\ ferromagnetic NWs using magnetic-field assisted dielectrophoresis' by Sachin K. Singh et al., RSC Adv., \\ 2020, 10, 39763-39770, DOI: 10.1039/DORA08381J.
}

DOI: 10.1039/dOra90121k

rsc.li/rsc-advances

The author regrets that the funding information was incorrectly shown in the acknowledgements section of the original manuscript. The corrected funding acknowledgement is as shown below.

All authors acknowledge support for this work, in part, from the National Science Foundation under Grant No. 1609303. A. S. and S. K. S. also acknowledge support, in part, from the National Science Foundation under Grant No. 1655496 and 1661038. The electrokinetics module used in the presented NanoMagnetoElectrokinetic modeling framework was developed with support from these grants.

The Royal Society of Chemistry apologises for these errors and any consequent inconvenience to authors and readers. 